\title{
MULTI-WEIGHTED BOUNDEDNESS FOR MULTILINEAR ROUGH FRACTIONAL INTEGRALS AND MAXIMAL OPERATORS
}

\section{XIANGXING TAO AND YANLONG SHI}

Abstract. In this article, several sufficient conditions on the weights $(\vec{v}, u)$ are given such that the multilinear rough fractional integrals $I_{\Omega, \alpha}^{(m)}$ and the rough multi-sublinear fractional maximal operators $M_{\Omega, \alpha}^{(m)}$ are bounded from the product spaces $L_{v_{1}}^{p_{1}}\left(\mathbb{R}^{n}\right) \times L_{v_{2}}^{p_{2}}\left(\mathbb{R}^{n}\right) \times \cdots \times L_{v_{m}}^{p_{m}}\left(\mathbb{R}^{n}\right)$ to the space $L_{u}^{q}\left(\mathbb{R}^{n}\right)$. The weak multi-weighted boundedness has also been derived. These results will extend the early and recent works in this direction.

Mathematics subject classification (2010): Primary 42B20, 42B25.

Keywords and phrases: Multilinear fractional integral, multi-sublinear fractional maximal function, rough kernel, $\mathscr{A}_{p, q}^{\alpha, r, t}$ weight.

\section{REFERENCES}

[1] S. Chanillo, D. K. Watson And R. L. Wheeden, Some integral and maximal operators related to starlike sets, Studia Math. 107 (1993), 223-255.

[2] X. Chen And Q. Xue, Weighted estimates for a class of multilinear fractional type operators, J. Math. Anal. Appl. 362 (2010), 355-373.

[3] Y. Ding AND S. Z. LU, Weighted norm inequalities for fractional integral operators with rough kernel, Canad. J. Math. 58 (1998), 29-39.

[4] J. García-Cuerva AND José María MARTEll, Two-weight norm inequalities for maximal operator and fractional integrals on non-homogeneous spaces, Indiana Univ. Math. J. 50 (2001), 12411280.

[5] L. Grafakos, On multilinear fractional integrals, Studia Math. 102 (1992), 49-56.

[6] L. Grafakos AND R. Torres, Multilinear Calderón-Zygmund theory, Adv. Math. 165 (2002), $124-164$.

[7] L. GRAFAKOS AND R. TORRES, Maximal operator and weighted norm inequalities for multilinear singular integrals, Indiana Univ. Math. 51 (2002), 1261-1276.

[8] A.K. Lerner, S. Ombrosi, C. Pérez, R.H. Torres, R. Trujillo-GonzÁlez, New maximal functions and multiple weights for the multilinear Calderón-Zygmund theory, Adv. Math. 220 (2009), $1222-1264$.

[9] C. E. Kenig And E. M. Stein, Multilinear estimates and fractional integration, Math. Res. Lett. 6 (1999), 1-15.

[10] K. Moen, Weighted inequalities for multilinear fractional integral operators, Collect. Math. 60 (2009), 213-238.

[11] B. MuCKENHOUPT AND R. L. WheEdEN, Weighted norm inequalities for fractional integrals, Trans. Amer. Math. Soc. 192 (1974), 261-274.

[12] C. PÉREZ, Two weighted norm inequalities for potential and fraction maximal operators, Indian Univ. Math. J. 43 (1994), 663-683.

[13] E. SAWYER, R. L. WHEEDEN, Weighted inequalities for fractional integrals on euclidean and homogeneous spaces, Amer. J. Math. 114 (1992), 813-874.

[14] Y. L. SHI, X. X. TAO, Boundedness for multilinear fractional integral operators on Herz type spaces, Applied Mathematics, A J. Chinese Univ. Ser. B, 23 (2008), 437-446. 
[15] X. X. TAO, Y. L. SHI AND S. Y. ZHANG, Boundedness of multilinear Riesz potential on product of Morrey and Herz-Morrey spaces, Acta Math. Sinica, Chinese Series, 52 (2009), 535-548. 